First Publication of Subtests in the Stanford-Binet 5, WAIS-IV, WISC-V, and WPPSI-IV Aisa Gibbons and Russell T. Warne

Utah Valley University

This manuscript has been accepted for publication in its current form. Please cite as:

Gibbons, A., \& Warne, R. T. (2019). First publication of subtests in the Stanford-Binet 5, WAIS-IV, WISC-V, and WPPSI-IV. Intelligence, 75, 9-18. doi:10.1016/j.intell.2019.02.005

Aisa Gibbons, Department of Behavioral Science, Utah Valley University; Russell T. Warne, Department of Behavioral Science, Utah Valley University.

Correspondence concerning this article should be addressed to 1243 Hillside Drive, Pleasant Grove, UT 84602. Email: aisagibbons@gmail.com 


\begin{abstract}
In this article we describe the origins of the subtests that appear on the modern Stanford-Binet Intelligence Scales (SB5), Wechsler Preschool and Primary Scale of Intelligence (WPPSI-IV), Wechsler Intelligence Scale for Children (WISC-V), and Wechsler Adult Intelligence Scale (WAIS-IV). We found that the majority of these subtest formats were first created in 1908 or earlier and that only three have been created since 1980 . We discuss the implications of this findings, which are that (1) many subtests have lengthy research histories that support their use in measuring intelligence; (2) many subtests have formats that predate modern theories of test creation, cognitive psychology, and intelligence; and (3) the history of many subtests is more complex than psychologists probably realize.
\end{abstract}


First Publication of Subtests in the Stanford-Binet 5, WAIS-IV, WISC-V, and WPPSI-IV

One of the first successes in applied psychology was the development of intelligence tests. Early tests in the 1910's and 1920's found rapid, widespread acceptance, with millions of American examinees tested every year (Cronbach, 1975; Thorndike, 1975; Yerkes, 1921). The use of these tests persists today, and in the 21 st century the most popular individually administered intelligence tests are the Stanford-Binet Intelligence Scale (SB5) and the Wechsler Intelligence Scales, the latter of which are the Wechsler Adult Intelligence Scale (WAIS-IV), the Wechsler Intelligence Scale for Children (WISC-V), and the Wechsler Preschool and Primary Scale of Intelligence (WPPSI-IV). These instruments have dominated intelligence testing for decades. The original version of the Stanford-Binet scale was first published over 100 years ago (Terman, 1916), though many of the items were direct translations or close adaptations of items from Binet's 1905, 1908, and 1911 intelligence scales. Ironically, Binet and Terman had opposite goals in their work on intelligence testing. Binet aimed to identify children who were struggling academically (Wolf, 1973), while Terman had an interest in identifying gifted children — an interest which started with his dissertation (Terman, 1905) and lasted until his death. Indeed, Terman's research on gifted children is his work that Terman is best remembered today (Warne, 2019). The Stanford-Binet has been revised several times since 1916, with the fifth edition, published in 2003, being the most recent.

The first Wechsler scale appeared in 1939 as the Wechsler-Bellevue, an intelligence test designed for adult examinees (see description in Wechsler, 1944), as opposed to the child examinees that Terman designed the Stanford-Binet for. Wechsler disapproved of the heavily verbal content of the early versions of the Stanford-Binet and of the test's ability to produce a 
global IQ as the only measure of a person's intellectual level (Wechsler, 1944). Therefore, he designed his test to produce a verbal and performance (i.e., non-verbal) IQ score. To create the Wechsler-Bellevue, Wechsler evaluated item formats that appeared on prior scales and selected the ones which he thought were the best measures of intelligence, based on his research (Boake, 2002; Wechsler, 1944) and his experience administering the Army Alpha and Army Beta in Texas during World War I (Yerkes, 1921, pp. 40, 80). As he wrote, “Our aim was not to produce a set of brand new tests but to select, from whatever source available, such a combination of them as would best meet the requirements of an effective adult scale" (Wechsler, 1944, p. 76). Wechsler favored test formats and items that (a) showed high discrimination in intelligence across much of the continuum of ability, (b) produced scores with high reliability, (c) correlated strongly with other widely accepted measures of intelligence, and (d) correlated with "pragmatic" subjective ratings of intelligence from people who knew the examinee — such as a work supervisor (Wechsler, 1944). These criteria led Wechsler to believe that, for example, an information subtest was effective but that the Army Beta's cube analysis subtest was not (because the latter was incapable of discriminating among people with intellectual disabilities). The success of the scale led Wechsler to create a separate test for children (the WISC) in 1949 and another for preschool children (the WPPSI) in 1967. All Wechsler tests have been revised several times since their creation (Kaplan \& Saccuzzo, 2018).

Throughout the years, however, psychologists have updated these tests with new analyses and norm samples, while also adding or removing subtests. Despite the revisions that have occurred over the decades, the revisers of the Wechsler scales or the Stanford-Binet have never completely replaced every subtest when updating an intelligence scale. The result is that 
contemporary versions of these tests are an amalgamation of old subtest formats and modern test construction methods.

It is the legacy of these old subtests on modern tests that intrigued us. Knowing that many subtests on the Stanford-Binet or the Wechsler scales long predate the current versions of these tests, we investigated the origins of these subtests, hoping to find the earliest publication of the subtest format in the scholarly literature. Throughout the history of the changes to the subtests, there has never been a compilation of the origins of the subtests on popular intelligence scales. Considering many of the subtests that have long been part of the SB or the Wechsler scales are still in use today, it is important to understand where they came from. The origin of these subtests provides valuable information about the creation of the SB and Wechsler scales and may shed light on test theory and test score interpretation. We believed that understanding the history of subtests would lead intelligence test users to have a greater appreciation of these subtests.

Moreover, we have engaged in this historical research with the goal of correcting misconceptions that psychologists have about the origin of frequently used intelligence subtests. For example, in one article the authors claimed that Corsi invented the block tapping task in 1972 (Wongupparaj, Wongupparaj, Kumari, \& Morris, 2017, p. 72). In reality, we show below that the task was invented in 1913. Likewise, we found multiple sources (e.g., Boake, 2002; Frank, 2013) that stated that the picture completion subtest (found on the WAIS-IV) originated with Healy (1914), but we discovered that Healy's task is different from the modern subtest, which originated with Binet (see below). We believe that such misconceptions are probably common. An incorrect understanding of the origin of a subtest may limit the thoroughness of literature searches about psychometric validity or the Flynn effect. Finally, research about the 
subtests' psychometric properties outside of the context of the SB or Wechsler scales can strengthen scientists' interpretations of what these tests measure.

\section{Search Procedures}

The task of identifying the origin of subtests may seem easy at first glance, but there are circumstances that make the task difficult. When the SB or Wechsler scales were first created or later updated, the test creators or revisers often did not state any origins of the subtests on their scales, let alone provide any citations for the first description of subtests. Modern test manuals for these tests are silent on the issue of the origin of their subtests, probably because many readers do not find information on the origins as important as technical data (e.g., validity of interpretations and score reliability), administration instructions, or interpretive guidelines. Lastly, throughout their history, many of these subtests have been known by different names or were changed slightly (e.g., from written format to oral). These changes sometimes made it hard to track down a particular subtest's origin.

Our search procedures for these tests started with a careful reading of lengthy accounts of the early history of intelligence testing (Boake, 2002; Matarazzo, 1972; Peterson, 1926/1969; Wolf, 1973; Young, 1924). When these works discussed a particular subtest that resembled a subtest on a modern Wechsler scale or the Stanford-Binet 5, we investigated literature that the author cited so that we could track down the original source of the subtest. We did the same for two sources about the history of a specific subtest (Richardson, 2005, 2011). Additionally, we consulted the manuals for the original Stanford-Binet (Terman, 1916), the Army Alpha and Army Beta (Yerkes, 1921), and we read English translations of Binet's reports of his original scales (Binet 1911/1916; Binet \& Simon, 1905a/1916, 1908/1916) to understand which subtests appeared on these influential instruments and to try to link them with modern subtests. Finally, 
we conducted searches of each subtest's names in Google Scholar and PsycInfo in an effort to search for any earlier mentions of the subtests than what we had found.

We conducted all searches for each individual subtest, and we never searched for multiple subtests' origins at the same time. Once we identified an early use of a subtest, we verified that the description did indeed correspond to modern intelligence subtests. (This was important because sometimes a verbal description, such as "picture completion," did not correspond to a modern subtest.) In an effort to verify that we had indeed found the earliest publication or description of a test, we would then search for earlier sources than what we had found. To do this, we first searched the source's citations in an effort to find any earlier indications of the subtest's use in the scholarly literature. We also conducted searches of scholarly databases using terminology we found in the article to look for earlier sources. When we exhausted these avenues and failed to find any earlier sources, we stopped the search for an earlier publication of a subtest.

\section{Subtests}

Table 1 lists all of the subtests found in the Stanford-Binet 5, the WAIS-IV, the WISC-V, and the WPPSI-IV. Subtests with very similar formats are combined into a single row. For example, the WISC-V Digit Span, WAIS-IV Digit Span, WISC-V Picture Span, and WISC-V Letter-Number Sequencing all require examinees to repeat in order a sequence of stimuli that have been presented. Although the stimuli and/or difficulty differ, the required tasks are all sufficiently similar that we saw the later subtests (e.g., WISC-V Letter-Number Sequencing) as an adaptation of the original test (i.e., the Digit Span subtest). Thus, for each row in Table 1 we only searched for a single subtest origin. Finally, readers should note that the subtests in Table 1 
and in the rest of this section are listed in alphabetical order; when subtests are combined, we listed the most widely known name for the subtest first.

\section{INSERT TABLE 1 ABOUT HERE.}

\section{Arithmetic/Verbal \& Nonverbal Quantitative Reasoning}

Arithmetic items consist of questions relating to mathematics such as addition, subtraction, multiplication, and division and have been on intelligence tests for a long time. According to Wechsler, arithmetic items were used as a, "rough and ready measure of intelligence," as early as the late 1800s (1944, p. 82). Arithmetic items were common on academic achievement tests before Binet, but these questions would not have been standardized among different tests. Not only were arithmetic tests found on the original Wechsler scales, but these types of items can also be found on the Army Alpha (Yoakum \& Yerkes, 1920), Binet's scales (in questions like, “Counting 4 single sous," were found on the 1908 scale; Binet \& Simon, 1908/1916), and on a test of reasoning ability created by Bonser (1910), though these do not predate Binet and Simon's (1908) use. Stone (1908) also created a standardized arithmetic test that resembles items found on early intelligence tests, though it is unclear whether his work had any influence on the creators or revisers of the Stanford-Binet or Wechsler tests.

The verbal quantitative reasoning subtest found on the Stanford-Binet 5 consists of items where subjects are asked to count, perform addition and subtraction problems, and name numbers. This test is extremely similar to arithmetic, so we believe that it has the same origin as the arithmetic subtest.

Due to the demand recently to have more nonverbal items on intelligence scales, a nonverbal quantitative reasoning subtest was formed for the SB5. The main difference between nonverbal and verbal quantitative reasoning is that the verbal version of the test has the questions 
written in words and numbers, while the nonverbal version uses pictures to ask arithmetic questions. Even though the nonverbal quantitative reasoning subtest uses pictures instead of words, its origins can be traced back to the same place as arithmetic items (which use words to ask math questions). Verbal arithmetic-like items have not only been found on the early Binet scales (Binet \& Simon, 1908/1916), but have also been used to quickly measure intelligence even before psychometrics was developed (Wechsler, 1944). It is likely that these types of items were also used on exams such as academic achievement tests. Nonverbal forms of arithmetic questions may have been used for other academic purposes as well, but the first time nonverbal quantitative reasoning items have been found on an intelligence scale is in the latest version of the SB5.

\section{Block Design}

In the block design subtest on the Wechsler tests, the examinee recreates a picture or model they have seen with blocks. This subtest was first published in Kohs's 1920 article, "The Block-Design Tests.” Kohs stated in the opening paragraphs of his article that his goal was to create a performance task that could measure intelligence without using language in the instructions or executing the task. According to Boake (2002), Kohs based his cube task on a game of the time named Color Cubes, which were being used already in classrooms to teach children to imitate visual designs and learn colors (e.g., The Special Class Teachers' Club, 1917).

\section{Block Span}

In the block span subtest, an examinee is shown an array of blocks, which the examiner taps in a predetermined order. The examinee must then repeat the sequence of taps. (In some intelligence test batteries, this test is called the Corsi block test; we call it "block span" because 
this is its name on the SB5.) Although the block span subtest resembles the more common digit span subtest (see below), the two subtests have different origins. The block span task has its roots traced back to Knox’s (1913) Cube Imitation Test, which was designed as part of a non-verbal test battery to identify immigrants at Ellis Island who had intellectual disabilities (Richardson, 2011). In Knox's original version, the examiner would tap a series of larger cubes in a predetermined order with a smaller cube; the examinee was to then use the smaller cube to repeat the sequence. In later versions, the smaller cube was replaced with another object, generically called a "pawn" (Richardson, 2005). In the modern SB5 block span subtest, the pawn has been removed from the test, with the examinee instead using their fingers to tap the blocks in the order they are shown. It is interesting to note that because screening immigrants was a task for physicians, Knox had a distinctly medical viewpoint of intellectual disabilities and recommended that only physicians administer his test battery, including the cube imitation test.

\section{Cancellation}

In the cancellation subtest, examinees are given a paper with a wide variety of random symbols on it (e.g., jumbled letters of the alphabet). The examinee is also told to cross out every example of a particular target symbol that they can find (e.g., every "B"). The earliest mention we can find of this test comes from Peterson (1926/1969, pp. 79-80), who stated that Oehrn reported in his 1889 dissertation a cancellation test of sorts that would ask the subjects to find certain letters. Oehrn's cancellation test was one of three that he used to measure "perception," the others requiring examinees to count the number of letters printed randomly on a page and to notice errors as they proofread a passage (Peterson, 1926/1969; Spearman, 1904).

\section{Coding/Animal Coding}


In the coding subtest, examinees are given a key for symbols and are asked to decode a message based on that same key. For example, the key could be as simple as $1=\mathrm{A}, 2=\mathrm{B}$, etc. With this sort of code, the examinee would then be asked to encode a message, like converting "cat" to "3-1-20". An influential use of the coding subtest was the "digit symbol subtest" found on the Army Beta (Yerkes, 1921; Yoakum \& Yerkes, 1920), which required examinees to convert numbers to geometric symbols. The Army Beta creators credited the first appearance of a coding subtest to Pyle's (1913) book, where he called it the "substitution test." However, Dearborn (1910) seems to be the first researcher to use this type of subtest. In his study, Dearborn gave different tasks to college students in their classroom. One of them was "The Practice Experiment," which strongly resembles the modern-day coding subtest. Dearborn (1910) believed that this task could measure the speed at which a person could master a new piece of information (i.e., the code) and reproduce it. However, it is important to notice, that Dearborn administered the task across multiple days, whereas modern tests only administer coding tasks on a single day.

\section{Comprehension}

During a comprehension subtest, the subject is asked to produce the answer to a question that is not considered a "fact," but which can be answered using previously learned informal knowledge. Wechsler (1944) acknowledged that comprehension questions predate the creation of his instruments. The original questions seem to appear on Binet's original scale (Binet \& Simon, 1905a/1916) under the section titled "Reply to an Abstract Question," as well as the 1908 scale (under the subtest titled "Comprehension Questions"; see Binet \& Simon, 1908/1916). One example from the third version of Binet's test is, "When one breaks something belonging to another what must one do?" (Binet, 1911/1916, p. 224). In his original scale, Binet stated that, 
"This test is one of the most important of all, for the diagnosis of mental debility" (Binet \& Simon, 1905a/1916, p. 65). Wechsler (1944) also mentions that comprehension tests are those that involve common sense, knowledge of practical information, and the ability to use past experience (p. 81).

\section{Delayed Response}

In the delayed response subtest on the SB5 there are three cups with a toy under them. After mixing the three cups around, the examinee tries to select the cup has the toy underneath it. According to Roid and Barram (2004), this subtest is based on the "classic shell game" (p. 39), and is a measure of short-term memory. The "classic shell game" has been used in criminal activity (e.g., three-card monte) and as a magic trick. (However, it is important to note that the delayed response subtest found on the SB5 lacks the deception of the classic shell game or a sleight-of-hand trick.) Though the SB5 seems to be the first time that the shell game has appeared on an intelligence scale, this task long predates intelligence tests. Apparently, this game came to America in the 18th century from England as a variant called "thimble-rig" (Maurer, 1947). Though thimble-rig was played with thimbles instead of cups, it still had the basic concept of the subject determining which cover had the object underneath it. Different versions of thimble-rig are still played today and have been for centuries.

\section{Digit Span/Picture Span/Letter-Number Sequencing}

In the digit span subtest, the examiner verbally gives a series of one-digit numbers which the subject must repeat. In some variants (often called backward digit span or reverse digit span), the subject must repeat the sequence backwards. The picture span subtest is extremely similar; during the task, the examinee is shown a set of pictures and then the subject must select the pictures (preferably in a specified order) from a different array of images. The letter-number 
sequencing subtest consists of verbally giving the examinee a set of numbers and letters and then asking the examinee to repeat them back in alphabetical and numerical order.

The origin of the digit span subtest was an article by Jacobs (1887) in which he described studies on school-age children in which the examiner read numerals out loud twice and then required the subjects to repeat the numbers (either aloud or written on paper). Jacobs was inspired by Ebbinghaus's research memorizing nonsense symbols, and he believed that the digit span task would have more accessible stimuli as a test of short-term memory capacity. This task found its way to the 1905 version of Binet's scale, where it was named "Repetition of Three Figures" (Binet \& Simon, 1905a/1916) because Binet had his examinees repeat back three numbers (figures) that the examiner gave orally. It is not clear whether Binet was aware of Jacobs's (1887) article, but Jacobs showed that performance on digit span was better for successively older children. This age progression in performance was a characteristic that Binet saw as desirable in a task because he believed that intellectual ability increased (on average) with age in children.

Digit span is a perennially popular subtest on intelligence tests, and innovations are not unusual. Terman (1916, p. 207) credited Bobertag with inventing the backward digit span test in 1911. Blair (1957) suggested a nonverbal task which we see as the precursor to the modern picture span subtest on the WAIS-IV and WISC-V. Blair's task was designed to measure memory span in deaf and hearing children by showing young examinee a series of cards with visual stimuli; the child must then point to the stimuli in the same order on a set of identical response cards. Modern users of the WISC-V and WAIS-IV are familiar with the letter-number sequencing subtest, which requires the series of stimuli to be repeated in either ascending order (for numbers) or alphabetical order (for letters). This subtest appeared on the WAIS-III 
(Wechsler, 1997) and the version of the Wechsler Memory Scale that appeared the same year. We see all of these tasks as adaptations of the original digit span task that Jacobs (1887) proposed.

\section{Early Reasoning}

The SB5 includes the early reasoning subtest, which requires the young examinee to use pictorial stimuli and tell a story about the image based on visual cues. The second Binet scale (Binet \& Simon, 1908/1916) is a clear predecessor for this test; the 1908 scale has three images, each containing at least one human figure. The child then was asked to describe the picture, and more complex responses based on interpretation (rather than simply naming objects in the image) were viewed as indicative of greater intellectual ability. Binet found this subtest so useful when diagnosing intellectual disabilities that he wrote, "Very few tests yield so much information as this one. ... We place it above all the others, and if we were obliged to retain only one, we should not hesitate to select this one" (Binet \& Simon, 1908/1916, p. 189).

\section{Figure Weights}

In the figure weights subtest found on the WISC-V and WAIS-IV, the examinee is shown an image of scales with different weights on both sides. The examinee then chooses what type of weights would balance a third scale. The figure weights task seems to be most similar to the original Piagetian balance beam task, which Inhelder and Piaget introduced in 1955 as a task that can indicate whether a child has reached the formal operational stage of reasoning (de Ribaupierre \& Lecerf, 2006). The main difference between the two is that figure weights is twodimensional (on paper) and is only based on different colors and shapes while the Piagetian balance beam task uses actual weights in the item administration process. Even so, the Piagetian balance beam task is a clear precursor to the figure weights subtest. 


\section{Form Board/Form Patterns/Visual Puzzles/Object Assembly}

The form board and form patterns subtests contain tasks that ask the examinee to match geometric shapes to other geometric shapes. Early versions of the form board resembled modern puzzles for young children, with wooden pieces that had to be placed into matching shapes that were cut into a wooden board. Form boards are among the oldest subtests still in use today; Jean Marc Gaspard Itard was the first to use a form board-like task when he studied and educated a young boy found in the wild (named the "wild boy of Aveyron") in 1798. Itard's successor and colleague, Édouard Séguin, made more permanent versions of the same test, and Séguin's widely read descriptions of form boards resulted in their popular usage among psychologists and physicians studying and training children and individuals with intellectual disabilities (Richardson, 2011; Sylvester, 1913).

The very similar visual puzzles and object assembly subtests have an origin in the puzzles used for entertainment and geography education, which were first created in the 1750 s in England and were in widespread use in the early 20th century when the first intelligence tests were being created (Norgate, 2007). Both form boards and visual puzzles/object assembly were incorporated into nonverbal testing settings (Richardson, 2011), and a paper-and-pencil version of object assembly - in which the examinee must divide a square to show how a set of two or three shapes can form the entire square - was present on the Army Beta (Yoakum \& Yerkes, 1920).

\section{Information}

According to Wechsler (1944), "Questions formulated to tap the subject's range of information have, for a long time, been the stock in trade of psychiatric examinations, and prior to the introduction of standardized intelligence tests they were widely used by psychiatrists in 
estimating the intellectual level of patients" (p. 77). The original Binet scale also had information items, such as, "Giving the name of four common coins," and asking the examinee to give their age (Binet \& Simon, 1905a/1916). Binet and Simon (1905b/1616) gave explicit credit to the French physicians Blin (1902) and Damaye (1903) for these items about topics that it was reasonable to expect a person to be exposed to a given culture to know. The original items that inspired Binet covered a variety of topics, including questions about the body and age in general; they are clear sources for the information subtest on modern intelligence tests. However, Hall (1893, pp. 16-22) published a series of items administered to children in two cities. While most of these were vocabulary items and whether the child had seen certain items or events (e.g., seen a watchmaker at work, or seen an axe), some of them include information-type items. Examples of these include whether they know "That leathern things come from animals," "What bricks are made of," and "Origin of butter" (all examples form Hall, 1893, p. 20). Hall (1893) believed that effective teaching required relating new information to what the child already knew; therefore, an understanding of children's vocabulary and information about the world around them would be pedagogically useful. While the information items Hall (1893) used do not seem to have influenced Binet, Terman did acknowledge their influence on early Stanford-Binet information subtests (Terman, 1924, p. 111).

Many later psychologists created their own information items that were culturally appropriate for their examinees. An example of this is on the Army Alpha, which has the following information item: "The pitcher has an important place in a) tennis b) football c) baseball d) handball" (Yoakum \& Yerkes, 1920, p. 274).

\section{Last Word}


In the last word subtest on the SB5 the examinees are (1) asked a question, (2) prompted to answer, and then (3) asked to remember the last word of the question. Roid and Barram (2004, p. 49) say that the last word subtest is based on a task reported by Daneman and Carpenter's (1980) study, making it one of the newest subtests found on the SB5 and the modern versions of the Wechsler scales. Daneman and Carpenter (1980) created this task to measure working memory capacity in college students.

It is important to note the differences between the modern SB5 last word subtest and Daneman and Carpenter's (1980) task. The earlier authors had their subjects read different sentences aloud and then recall the last word of each sentence (in the order that the sentences were presented) after reading the final sentence. Moreover, Daneman and Carpenter (1980) did not require examinees to answer a question. Despite the differences, the connection with Daneman and Carpenter's test is undeniable.

\section{Matrices (Object Series/Matrix Reasoning)}

While taking the matrices test, the subject is shown a pattern of geometric figures and is asked to complete the pattern. Although the SB5 and all the modern Wechsler tests contain matrix items, the best-known test to use matrix items is the Raven's tests (the Raven's Coloured Progressive Matrices, Raven's Progressive Matrices, and Raven’s Advanced Progressive Matrices), a series of nonverbal matrices tests that are extremely good measures of fluid intelligence. Because the Raven name has always been associated with matrix items, the origin of this subtest is not obscure. Penrose and Raven (1936) were the first to describe a matrix, though Raven's (1939) article is a more widely known early report of matrix items. Matrix tasks were designed to be a measure of "innate mental capacity" (Penrose \& Raven, 1936, p. 7) that did not rely heavily on language or educational experiences. 


\section{Memory for Sentences}

In the memory for sentences subtest, the examinee must repeat back a sentence that is read to them. The 1905 Binet Scale subtest titled "Repetition of 15 Word Sentences," in which the examinee was also supposed to repeat back a sentence (Binet \& Simon, 1905a/1916). But according to Wolf (1973, pp. 86-87), Binet and Victor Henri used a memory for sentences test as early as 1892, and this earlier work presaged Binet's use of the subtest on his first intelligence scale. Consistent with Binet's emphasis on studying complex mental capacities instead of simple abilities, Binet believed that memory of entire sentences was more useful as a measure of cognitive development than memory for isolated words. Memory for sentences had a sharper age performance gradient than for memory of isolated words, which Binet saw as a useful characteristic in mental tasks (Wolf, 1973, p. 87).

\section{Picture Absurdities}

In a picture absurdities subtest, an examinee is shown a picture that has something wrong or absurd in it. The examinee then must explain what is "absurd" about the picture. For example, a picture might depict a firefighter holding a hose, but with flowers emerging from his hose, instead of water. Although conceptually similar to the verbal absurdities subtest (see below), the picture absurdities subtest emerges independently years later. The earliest description of this subtest in English is Terman and Chamberlain's (1918) description of an "absurd pictures" subtest containing images, such as "A man with three legs," and a man smoking an upside pipe. Terman claimed in this article that he was inspired in 1914 by a "picture puzzle" in a children's magazine in which many objects within a picture were ". . so drawn as to contain an absurdity" (Terman \& Chamberlain, 1918, pp. 347-348). However, in this description, Terman also mentioned that he was unaware of Rossolimo's "test of this kind." No exact citation to 
Rossolimo's test is given, but we found two references in 1911 to works by Rossolimo that could have been Terman's sources. One article in English contains an offhand mention of a test of "pictures containing absurdities" to measure "comprehension" (Rossolimo, 1911a, p. 212). A second, more detailed article in German describes a picture absurdities subtest containing 30 images (10 for children, 10 for uneducated adults, and 10 for educated adults) as part of a mental test battery (Rossolimo, 1911b, pp. 278-279). This article does not reproduce any of the images, but the descriptions clearly describe images that would be on a picture absurdities subtest. For example, one item for children consisted of, "A lady is reading a book with her eyes blindfolded, with glasses put over the bandage" (Rossolimo, 1911b, p. 278, translated via Google translate). These two articles by Rossolimo are the earliest record of a picture absurdities subtest we have found.

\section{Picture Completion}

During the picture completion subtest, the examinee is shown pictures that have something missing. The examinee is then asked to fill in whatever is missing in the picture. The picture completion subtest's origin can be traced to Binet's 1908 subtest called 'Unfinished Pictures" (Binet \& Simon, 1908/1916). Both the original subtest and its modern equivalent on the WAIS-IV have similar instructions, though the artwork is much more sophisticated in the modern subtest. Figure 1 shows some examples of the "Unfinished Pictures" task found on the 1908 Binet-Simon scale. Picture completion items were also found on the Army Beta (Yoakum \& Yerkes, 1920).

\section{INSERT FIGURE 1 ABOUT HERE.}

\section{Picture Memory/Picture Naming}


During the picture memory subtest, examinees are briefly shown some images and afterwards are then asked to choose from a new group of pictures the images they had previously seen. Binet's original scale has a subtest titled "Exercise of Memory of Pictures" (Binet \& Simon, 1905a/1916), which he called “. . . a test of attention and visual memory” (p. 60). The original version of this task shares the same format of presenting a pictorial stimulus and then asking the examinee to recall it later.

\section{Position and Direction}

The position and direction subtest (found on the SB5) asks the examinee to move items based on commands that include words related to spatial position (e.g., "on," "inside"). More difficult items designed for older age groups ask the examinee to imagine rotating in various directions sequentially (e.g., "left," "right," "north," south") and then to state what direction the examinee would face after the hypothetical sequence is completed. Both types of items appear on the 1937 Stanford-Binet (Terman \& Merrill, 1937), but had been reported nearly twenty years before (Terman \& Chamberlain, 1918, pp. 344-345) as part of a pilot procedure for 23 subtests, many of which appeared on later intelligence tests.

\section{Procedural Knowledge}

In the procedural knowledge subtest, the subject is shown a series of cards and is asked to describe either how they use the object or perform the task shown in the card. In Wolf's 1973 biography of Binet, she mentioned that Damaye's (1903) study of normal cognitive development included several questions that resemble information items. One specific type of item they mentioned was asking the child about an object, especially asking them to describe the use of it (p. 173). This description highly resembles procedural knowledge. Even though there are slight differences in the fact that the modern procedural knowledge subtest uses cards and pictures, 
Blin and Damaye's question is the oldest description of an item resembling procedural knowledge.

\section{Similarities}

While taking the modern-day similarities tests, the examinee is asked to qualitatively define the relationship between a pair of words provided to them. The 1905 version of Binet's scale mentions a subtest called, "Resemblances of Several Known Objects Given from Memory" (Binet \& Simon, 1905a/1916). This subtest examined the subject's ability to compare common objects and state how they are similar. Earlier than this test, though, Binet and Henri suggested using a similarities task to measure comprehension in children as early as 1895 (Peterson, 1926/1969, p. 89).

In the picture concepts subtest, the examinee chooses which images among those provided all share a common characteristic. This focus on commonalities makes this subtest greatly resemble the similarities subtest, which requires examinees to identify how objects presented verbally are similar. We see the picture concepts subtest as having the same origin, which is Binet's 1905 subtest, "Resemblances of Several Known Objects from Memory” (Binet \& Simon, 1905a/1916). As far as we could find, the first time this picture form of a similarities subtest was published was as part of the WPPSI-III (Wechsler, 2002).

\section{Symbol Search/Bug Search}

In the symbol search subtest, the examinee is shown one or two target images and is then supposed to determine whether there is a matching symbol from another set of images. The WPPSI's bug search is a similar test, but with target images that are cartoon bugs (as ageappropriate stimuli). These subtests are similar to matching activities designed for children. As formatted for an intelligence test, though, it was first seen on the WISC-III (Wechsler, 1991), 
and it is seen as a measure of "perceptual organization, fluid intelligence, and planning and learning ability" (Weiss, Saklofske, Holdnack, \& Prifitera, 2016, pp. 13-14).

\section{Verbal Absurdities}

The verbal absurdities subtest consists of statements which have something false in them that the examinee is supposed to identify. In Binet's second test, he had a subtest named “Criticism of Sentences” (Binet \& Simon, 1908/1916, pp. 227-229). A memorable (though gruesome) example can be found on the 1908 Binet scale: "Yesterday they found on the fortification the body of an unfortunate girl, cut into eighteen pieces. It is believed that she killed herself" (Binet \& Simon, 1908/1916, p. 228). The same subtest (retaining some of Binet's sentences, including the one we quote, was called "Absurdities" in the 1916 Stanford-Binet (Terman, 1916). According to Wolf (1973, pp. 147-148), Binet suggested this type of test much earlier in 1896 as one of his measures of "comprehension."

\section{Verbal Analogies}

The current verbal analogies test first gives the examinee two words which the examinee must then understand the relationship between. Based on this relationship, the examinee is then supposed to generate a fourth word that has the same relationship with the third word that the first two words have with one another. The earliest mention we have been able to find of verbal analogy items is in an 1894 article by Binet when he suggested items that asked examinees to define the relationship between two words (Wolf, 1973). Using this item format, Binet believed that ". . . one would certainly arrive at a test of judgment and of other complex functions" (as quoted in Wolf, 1973, p. 93). For example, in Binet's version of analogies, the examinee would be asked to explain the relationship between the word spoon and soup. Though Binet's 1894 suggestion for a test isn't exactly the same as the current version of verbal analogies, it still asks 
the examinee to discover the relationship between two words. We see this as a clear precursor to modern verbal analogy items.

\section{Vocabulary/ Receptive Vocabulary}

Vocabulary subtest and receptive vocabulary subtest items require the examinee to define a word from a standardized list, whether in a multiple choice or free-response format. These types of items are on the current version of the Stanford-Binet and all three of the Wechsler intelligence scales, but predate the original versions of these modern tests. The first time that vocabulary items were seen on an intelligence test specifically was in Binet's original 1905 test (Binet \& Simon, 1905a/1916). Both Wolf (1973, p. 84) and Matarazzo (1972, p. 32) stated that Binet published a vocabulary test in 1890, a full 15 years before his first intelligence scale. However, vocabulary tests were part of educational testing in the 19th century and were not unique to the realm of intelligence testing (e.g., see Hall's, 1893, summary of an 1869 German report of the performance of 10,000 children on a German vocabulary test). These vocabulary tests often functioned as academic achievement tests, though Hall (1893) saw understanding a child's vocabulary as serving a foundation for future teaching (see the subsection the information subtest origin).

\section{Zoo Location}

A new subtest on the WPPSI-IV is the zoo location subtest. For this task, the examinees are shown zoo animals at a specific location on a simple two-dimensional map. Later, the examiner asks the child to place the zoo animals in the location that they were previously. A precursor of this subtest is the 7/24 test (originally created by Barbizet \& Cany, 1968), which required examinees to reproduce from recall a random pattern of 7 dots by placing round tokens on a 24-square grid. 


\section{Discussion}

Tracing the origins of all subtests found on the SB5, WAIS-IV, WISC-V, and WPPSI- IV is a project that has not been undertaken before. We wrote this article to give intelligence test users an appreciation for the history of these subtests and also explain more about the creation of the original scales. Perhaps with a knowledge that most subtests have been in use for many years, practitioners can have more confidence in their use of these item formats because they can know that these subtests have been subjected to repeated investigation for several decades.

Many of the origins of the modern subtests date back over a century. Indeed, the median year of publication for the subtests was 1908, and only three subtests originated after 1980. Most subtests on the Wechsler tests and SB5 have withstood the test of time and have accumulated a large body of validity research, proving their utility in measuring intelligence. Moreover, continuity in subtests gives researchers tools for longitudinal testing, research into development and aging, and the investigation of population-level trends (e.g., the Flynn effect). Using the same subtest formats over the decades also permits research and knowledge about how these items function to accumulate. A timeline showing our proposed candidates for the first publication of each test is displayed in Figure 2.

\section{INSERT FIGURE 2 ABOUT HERE.}

One discovery that we found striking was the diverse sources of inspiration for subtests. While the majority did have roots in the creation of cognitive tests, others have their origin in games (the delayed response subtest, the object assembly subtest), classroom lessons (the block design subtest), the study of a feral child (form boards and related subtests), school assessments (vocabulary subtest) and more. To us, this means that items on intelligence tests often have a connection with the real world - even when they are presented in a standardized, acontextual 
testing setting. Additionally, this undercuts the suggestion that critics of intelligence testing often make that intelligence test items are meaningless tasks that are divorced from any relationship to an examinee's environment (e.g., Gould, 1981).

On the other hand, one criticism of intelligence tests seems justified from our study: subtests that appear on popular intelligence tests have changed little in the past century (Linn, 1986). While one could argue that the enduring appeal of these subtests is due to their high performance in measuring intelligence, the fact remains that many of these subtests were often created with little guiding theory or understanding of how the brain and mind work to solve problems (Naglieri, 2007). While sophisticated theories regarding test construction and the interrelationships of cognitive abilities have developed in recent decades (e.g., Carroll, 1993), it is often not clear exactly how the tasks on modern intelligence tasks elicit examinees to use their mental abilities to respond to test items.

It is apparent from our research that as the creators and revisors of the Stanford-Binet and Wechsler tests have considered new item formats, they have taken inspiration (in a very direct way) from pre-existing item formats. From a pragmatic perspective, this makes sense; using an existing item format is easier than inventing a new one. Moreover, these item formats often had research supporting their use in intelligence testing, whereas a new subtest would not. Additionally, copyright laws only protect the exact item content - not the general format of a subtest. Therefore, we believe that most psychologists creating or revising the Wechsler or Stanford-Binet tests found it expedient to reuse existing item and subtest formats, which is why most subtest formats on modern intelligence tests are over 100 years old.

We also wish to draw the reader's attention to the fact that there have been many subtests developed that do not appear on current intelligence scales. An example of this is Porteus's 
(1915) maze task, which appeared on the Army Beta and in some iterations of the WISC.

Though the test functioned well as a non-verbal test of intelligence (see Porteus, 1965, for a review), other non-verbal tasks have surpassed it, and it does not appear on any Wechsler test today or the SB5. This demonstrates that intelligence testing is not a static technology. Rather, test creators and revisers frequently re-examine subtests to determine the best available tasks to include on an intelligence test. Likewise, there are some popular tests, like the WoodcockJohnson IV, Differential Ability Scales II, and the Kaufman Assessment Battery for Children II that are all more popular than the SB5. While there is overlap between these tests' subtests and the subtests we explored in this article, an exploration of the origin of the item formats used on these more popular tests would be beneficial.

Our work highlights the influence of a small number of intelligence tests: Binet's scales, the Army Alpha and Army Beta, the original Stanford-Binet, and the early Wechsler tests. Many of the subtests we examined either originated in these scales or reached a large audience of psychologists via the inclusion of these tests. Other tasks often are capable of measuring intelligence, such as executive functioning tasks (Brydges, Reid, Fox, \& Anderson, 2012), but these rarely find a place on the Wechsler or Stanford-Binet tests. Although we admire the work of the early pioneers of intelligence testing (Warne, 2019; Warne, Burton, Gibbons, \& Melendez, 2019), we believe that modern test revisers and creators would benefit from examining the work of modern cognitive psychologists for inspiration in creating new test formats.

We also wish to emphasize that even though subtest or item formats in some cases have been consistent through the decades, this does not imply that item content has remained unchanged. For example, words on vocabulary or information subtests have often changed as tests have been revised. Modern examinees who take these subtests do not receive the same 
questions as examinees did a hundred years ago; rather, the general format of the test item and what the examinee is asked to do is what is the same. Test creators and revisers regularly use the framework of a subtest's item format to create new stimuli to probe examinees' mental abilities. Indeed, test publishers now commonly revise intelligence tests at regular intervals to combat breaches in item confidentiality, the Flynn effect, and item drift that may develop over time.

It is important to recognize that many subtests on other intelligence scales can also be traced back to the early 20th century. For example, Binet's (1905a/1916) original scale contained a paper cutting task (suggested by Henri in 1898, according to Wolf, 1973, p. 150) in which the examiner folded a paper and then cut a portion out. The examinee then had to draw what the paper would look like unfolded. The SB5 and current Wechsler scales do not contain this subtest, but the current version of the Cognitive Abilities Test (Lohman \& Lakin, 2017) does. Lumosity, a company that creates "brain training" computer programs, even calls this task "Thurstone's punched holes," despite the fact that Thurstone did not invent the task (Simons et al., 2016). Likewise, Ramful, Lowrie, and Logan (2016) stated that this test had a 1970s origin—misstating the true creation of the test by over seven decades. Thus, it is likely that many other subtests have origins that are often misunderstood by psychologists.

Our historical research showed that some of the item formats found on the original BinetSimon scale predate their inclusion on the famous 1905 Binet intelligence scale. Binet's first article on the cognitive development of children was published in 1890 (Wolf, 1973, p. 81), and he pursued this line of work in almost total seclusion for over a decade (Wolf, 1973). Binet's lengthy practice in testing children's cognition provided knowledge and experience that he drew upon when he created his scales - a fact that has been noted by others scrutinizing the historical record (e.g., Nicolas, Andrieu, Croizet, Sanitioso, \& Burman, 2013). This contrasts with the 
overly simplistic version of the history of testing that psychology students are often exposed to in textbooks, which portray Binet's 1905 scale as a sudden revolution in psychological measurement (e.g., Coaley, 2014; Kaplan \& Saccuzzo, 2018). This version of history also ignores the contributions of individuals like Itard, Séguin, Henri, Damaye, and others who provided Binet with item formats that he would use in his scales.

Despite our best efforts to identify the origins of different intelligence scale subtests, we do not claim to have read every scholarly article about intelligence or cognitive testing that was published in the early decades of this field. Although we did successfully trace most subtests to publications that predate their first appearance on the SB or a Wechsler test, there is still the possibility that some tests appeared even earlier than we realized.

Regardless of specific changes to item content or the exact mix of subtests on an intelligence test, the majority of the subtests on the current versions of the Wechsler and Stanford-Binet intelligence scales have origins dating back more than a century. We encourage psychologists who use, study, or revise these tests - and other intelligence tests - to be aware of this lengthy history. For many of these subtests the psychometric literature extends far beyond the test manuals for the Wechsler and Stanford-Binet tests. Additionally, understanding the origins of the subtests on modern intelligence tests can also help psychologists appreciate the quality of these subtests, while also recognizing their shortcomings. 


\section{References}

Barbizet, J., \& Cany, E. (1968). Clinical and psychometrical study of a patient with memory disturbances. International Journal of Neurology, 7, 44-54.

Bell, J. C. (1921). Group tests of intelligence. An annotated list. Journal of Educational Psychology, 12, 103-108. doi:10.1037/h0073682

Binet, A., (1911/1916). New investigations upon the measure of the intellectual level among school children (E. S. Kite, trans.). In A. Binet \& T. Simon, The development of intelligence in children (the Binet-Simon Scale) (pp. 274-329). Baltimore, MD: Williams \& Wilkins.

Binet, A., \& Simon, T. (1905a/1916). New methods for the diagnosis of the intellectual level of subnormals (E. S. Kite, trans.). In A. Binet \& T. Simon, The development of intelligence in children (the Binet-Simon Scale) (pp. 9-36). Baltimore, MD: Williams \& Wilkins.

Binet, A., \& Simon, T. (1905b/1916). Upon the necessity of establishing a scientific diagnosis of inferior states of intelligence (E. S. Kite, trans.). In A. Binet \& T. Simon, The development of intelligence in children (the Binet-Simon Scale) (pp. 37-90). Baltimore, MD: Williams \& Wilkins.

Binet, A., \& Simon, T. (1908/1916). The development of intelligence in the child (E. S. Kite, trans.). In A. Binet \& T. Simon, The development of intelligence in children (the BinetSimon Scale) (pp. 182-273). Baltimore, MD: Williams \& Wilkins.

Blair, F. X. (1957). A study of the visual memory of deaf and hearing children. American Annals of the Deaf, 102, 254-263.

Blin, E. (1902). Les débilités mentales. Revue de Psychiatrie, 8, 337-356. 
Boake, C. (2002). From the Binet-Simon to the Wechsler-Bellevue: Tracing the history of intelligence testing. Journal of Clinical and Experimental Neuropsychology, 24, 383-405. doi:10.1076/jcen.24.3.383.981

Bonser, F. G. (1910). The reasoning ability of children of the fourth, fifth, and sixth school grades (Teachers College Contributions to Education, no. 37). New York, NY: Teachers College, Columbia University.

Brydges, C. R., Reid, C. L., Fox, A. M., \& Anderson, M. (2012). A unitary executive function predicts intelligence in children. Intelligence, 40, 458-469.

doi:10.1016/j.intell.2012.05.006

Carroll, J. B. (1993). Human cognitive abilities: A survey of factor-analytic studies. New York, NY: Cambridge University Press.

Coaley, K. (2014). An introduction to psychological assessment \& psychometrics. Thousand Oaks, CA: Sage.

Cronbach, L. J. (1975). Five decades of public controversy over mental testing. American Psychologist, 30, 1-14. doi:10.1037/0003-066X.30.1.1

Damaye, H. (1903). Eassai de diagnostic entre les états de débilités mentales. Paris, France: Steinheil.

Daneman, M., \& Carpenter, P. A. (1980). Individual differences in working memory and reading. Journal of Verbal Learning and Verbal Behavior, 19, 450-466. doi:10.1016/S0022-5371(80)90312-6

Dearborn, W. F. (1910). Experiments in learning. Journal of Educational Psychology, 1, 373388. doi:10.1037/h0073531 
de Ribaupierre, A., \& Lecerf. T. (2006). Relationships between working memory and intelligence from a developmental perspective: Convergent evidence from a neoPiagetian and a psychometric approach. European Journal of Cognitive Psychology, 18, 109-137. doi:10.1080/09541440500216127

Frank, G. (1983). The Wechsler enterprise: An assessment of the development, structure, and use of the Wechsler tests of intelligence. New York, NY: Pergamon Press.

Gould, S. J. (1981). The mismeasure of man. New York, NY: W. W. Horton.

Hall, G. S. (1893). The contents of children's minds on entering school. New York, NY: E. L. Kellogg \& Co.

Healy, W. (1914). A pictorial completion test. Psychological Review, 21, 189-203. doi:10.1037/h0075712

Jacobs, J. (1887). Experiments on “prehension.” Mind, 12(45), 75-79. doi:10.2307/1411258

Kaplan, R. M., \& Saccuzzo, D. P. (2018). Psychological testing: Principles, applications, and issues (9th ed.). Boston, MA: Cengage Learning.

Knox, H. A. (1913). The differentiation between moronism and ignorance. New York Medical Journal, 98, 564-566.

Kohs, S. C. (1920). The block-design tests. Journal of Experimental Psychology, 3, 357-376. $10.1037 / \mathrm{h} 0074466$

Linn, R. L. (1986). Educational testing and assessment: Research needs and policy issues. American Psychologist, 41, 1153-1160. doi:10.1037/0003-066X.41.10.1153

Lohman, D. F., \& Lakin, J. M. (2017). Cognitive Abilities Test (Form 8). Boston, MA: Houghton-Mifflin Harcourt. 
Matarazzo, J. D. (1972). Wechsler's measurement and appraisal of adult intelligence (5th ed.). Baltimore, MD: Williams \& Wilkins Company.

Maurer, D. W. (1947). The argot of the three-shell game. American Speech, 22, 161-170. doi: $10.2307 / 3181790$.

Naglieri, J. A. (2007). Traditional IQ: 100 years of misconception and its relationship to minority representation in gifted programs. In J. VanTassel-Baska (Ed.), Alternative assessments with gifted and talented students (pp. 67-88). Waco, TX: Prufrock Press.

Nicolas, S., Andrieu, B., Croizet, J.-C., Sanitioso, R. B., \& Burman, J. T. (2013). Sick? Or slow? On the origins of intelligence as a psychological object. Intelligence, 41, 699-711. doi:10.1016/j.intell.2013.08.006

Norgate, M. (2007). Cutting borders: Dissected maps and the origins of the jigsaw puzzle. Cartographic Journal, 44, 342-350. doi:10.1179/000870407X241908

Penrose, L. S., \& Raven, J. C. (1936). A new series of perceptual tests: Preliminary communication. British Journal of Medical Psychology, 16, 97-104. doi:10.1111/j.20448341.1936.tb00690.x

Peterson, J. (1969). Early conceptions and tests of intelligence. Westport, CT: Greenwood Press, Publishers. (Originally printed in 1926).

Porteus, S. D. (1915). Mental tests for feeble-minded: A new series. Journal of PsychoAsthenics, 19, 200-213.

Porteus, S. D. (1965). Porteus maze test: Fifty years' application. Palo Alto, CA: Pacific Books. Pyle, W. H. (1913). The examination of school children: A manual of directions and norms. New York, NY: The Macmillan Company. 
Ramful, A., Lowrie, T., \& Logan, T. (2016). Measurement of spatial ability: Construction and validation of the spatial reasoning instrument for middle school students. Journal of Psychoeducational Assessment, 35, 709-727. doi:10.1177/0734282916659207

Raven, J. C. (1939). The R.E.C.I. series of perceptual tests: An experimental survey. British Journal of Medical Psychology, 18, 16-34. doi:10.1111/j.2044-8341.1939.tb00705.x

Richardson, J. T. E. (2005). Knox's cube imitation test: A historical review and an experimental analysis. Brain and Cognition, 59, 183-213. doi:10.1016/j.bandc.2005.06.001

Richardson, J. T. E. (2011). Howard Andrew Knox: Pioneer of intelligence testing at Ellis Island. New York, NY: Columbia University Press.

Roid, G. H., \& Barram, R. A. (2004). Essentials of Stanford-Binet intelligence scales (SB5) assessment. Hoboken, NJ: John Wiley \& Sons.

Rossolimo, G. (1911a). Mental profiles: A quantitative method of expressing psychological processes in a normal and pathological cases. The Journal of Experimental Pedagogy, 1, 211-214.

Rossolimo, G. (1911). Die psychologischen profil. Klinik für psychische und nervöse Krankheiten, 6, 249-326.

Simons, D. J., Boot, W. R., Charness, N., Gathercole, S. E., Chabris, C. F., Hambrick, D. Z., \& Stine-Morrow, E. A. L. (2016). Do “brain-training” programs work? Psychological Science in the Public Interest, 17, 103-186. doi:10.1177/1529100616661983

Spearman, C. (1904). "General intelligence," objectively determined and measured. American Journal of Psychology, 15, 201-293. doi: 10.2307/1412107

The Special Class Teacher's Club. (1917). The Boston way: Plans for the development of the individual child. Concord, NH: The Rumford Press. 
Stone, C. W. (1908). Arithmetical abilities and some factors determining them (Contributions to education Teachers College series No. 19). New York, NY: Teachers College, Columbia University.

Sylvester, R. H. (1913). The form board test. Princeton, NJ: Psychological Review Company.

Terman, L. M. (1905). A study in precocity and prematuration. The American Journal of Psychology, 16, 145-183. doi:10.2307/1412123

Terman, L. M. (1916). The measurement of intelligence: An explanation of and a complete guide for the use of the standard revision and extension of The Binet-Simon Intelligence Scale. Cambridge, MA: Houghton Mifflin Company.

Terman, L. M. (1924). The mental test as a psychological method. Psychological Review, 31, 93117. doi:10.1037/h0070938

Terman, L. M., \& Chamberlain, M. B. (1918). Twenty three serial tests of intelligence and their intercorrelations. Journal of Applied Psychology, 2, 341-354. doi:10.1037/h0072077

Terman, L. M., \& Merrill, M. A. (1937). Measuring intelligence: A guide to the administration of the new revised Stanford-Binet tests of intelligence.

Thorndike, R. L. (1975). Mr. Binet's test 70 years later. Educational Researcher, 4(5), 3-7. doi: $10.2307 / 1174855$

Warne, R. T. (2019). An evaluation (and vindication?) of Lewis Terman: What the father of gifted education can teach the 21st century. Gifted Child Quarterly, 63, 3-21. doi:10.1177/0016986218799433

Warne, R. T., Burton, J. Q., Gibbons, A., \& Melendez, D. A. (2018). Stephen Jay Gould's analysis of the Army Beta test in The Mismeasure of Man: Distortions and 
misconceptions regarding a pioneering mental test. Journal of Intelligence, 7, 6. doi:10.3390/jintelligence7010006.

Wechsler, D. (1944). The measurement of adult intelligence (3rd ed.). Baltimore, MA: Williams \& Wilkins.

Wechsler, D. (1991). The Wechsler Intelligence Scale for Children (3rd ed.). San Antonio, TX: The Psychological Corporation.

Wechsler, D. (2002). The Wechsler Preschool and Primary Scale of Intelligence (3rd ed.). San Antonio, TX: The Psychological Corporation.

Wechsler, D. (2012). The Wechsler Preschool and Primary Scale of Intelligence (4rd ed.). San Antonio, TX: The Psychological Corporation.

Weiss, L. G., Saklofske, D. H., Holdnack, J. A., \& Prifitera, A. (2016). WISC-V assessment and interpretation: Scientist-practitioner perspectives. London, UK: Academic Press.

Wolf, T. H. (1973). Alfred Binet. Chicago, IL: The University of Chicago Press.

Wongupparaj, P., Wongupparaj, R., Kumari, V., \& Morris, R. G. (2017). The Flynn effect for verbal and visuospatial short-term and working memory: A cross-temporal meta-analysis. Intelligence, 64, 71-80. doi:10.1016/j.intell.2017.07.006

Yerkes, R. M. (1921). Psychological examining in the United States army. Washington, DC: Government Printing Office.

Yoakum, C. S., \& Yerkes, R. M. (1920). Army mental tests. New York, NY: Henry Holt and Company.

Young, K. (1924). The history of mental testing. The Pedagogical Seminary, 31, 1-48, doi:10.1080/08919402.1924.10532922 
Table 1

Subtests on the Current Versions of the Stanford-Binet and Wechsler Tests

\begin{tabular}{|c|c|c|c|c|}
\hline $\begin{array}{r}\text { Subtest Names }^{\mathrm{a}} \\
\end{array}$ & SB5 & WPPSI-IV & WISC-V & WAIS-IV \\
\hline Arithmetic/Verbal and Nonverbal & $\mathrm{X}$ & & $\mathrm{X}$ & $\mathrm{X}$ \\
\hline Quantitative Reasoning & & & & \\
\hline Block Design & & $X$ & $\mathrm{X}$ & $\mathrm{X}$ \\
\hline Block Span & $X$ & & & \\
\hline Cancellation & & $\mathrm{X}$ & $\mathrm{X}$ & $\mathrm{X}$ \\
\hline Coding/Animal Coding & & $X$ & $\mathrm{X}$ & $\mathrm{X}$ \\
\hline Comprehension & & $X$ & $X$ & $\mathrm{X}$ \\
\hline Delayed Response & $X$ & & & \\
\hline $\begin{array}{l}\text { Digit Span/Picture Span/Letter-Number } \\
\text { Sequencing }\end{array}$ & & & $X$ & $X$ \\
\hline Early Reasoning & $\mathrm{X}$ & & & \\
\hline Figure Weights & & & $\mathrm{X}$ & $\mathrm{X}$ \\
\hline $\begin{array}{l}\text { Form Board and Form Patterns/Visual } \\
\text { Puzzles/Object Assembly }\end{array}$ & $X$ & $X$ & $\mathrm{X}$ & $\mathrm{X}$ \\
\hline Information & & $\mathrm{X}$ & $\mathrm{X}$ & $\mathrm{X}$ \\
\hline Last Word & $\mathrm{X}$ & & & \\
\hline Matrices/Object Series/Matrix Reasoning & $\mathrm{X}$ & $\mathrm{X}$ & $\mathrm{X}$ & $\mathrm{X}$ \\
\hline Memory for Sentences & $X$ & & & \\
\hline Picture Absurdities & $\mathrm{X}$ & & & \\
\hline Picture Completion & & & & $\mathrm{X}$ \\
\hline Picture Concepts & & $\mathrm{X}$ & $\mathrm{X}$ & \\
\hline Picture Memory/Picture Naming & & $\mathrm{X}$ & & \\
\hline Position and Direction & $X$ & & & \\
\hline Procedural Knowledge & $\mathrm{X}$ & & & \\
\hline Similarities & & $\mathrm{X}$ & $X$ & $\mathrm{X}$ \\
\hline Symbol Search/Bug Search & & $\mathrm{X}$ & $X$ & $\mathrm{X}$ \\
\hline Verbal Analogies & $\mathrm{X}$ & & & \\
\hline Verbal Absurdities & $\mathrm{X}$ & & & \\
\hline Vocabulary/Receptive Vocabulary & $\mathrm{X}$ & $\mathrm{X}$ & $\mathrm{X}$ & $\mathrm{X}$ \\
\hline Zoo Locations & & $X$ & & \\
\hline
\end{tabular}

${ }^{a}$ Some subtests are listed as having multiple names because subtests from different instruments may have different names but formats that are so similar that we considered the subtests to be the same.

${ }^{b}$ Subtests are listed alphabetically. 

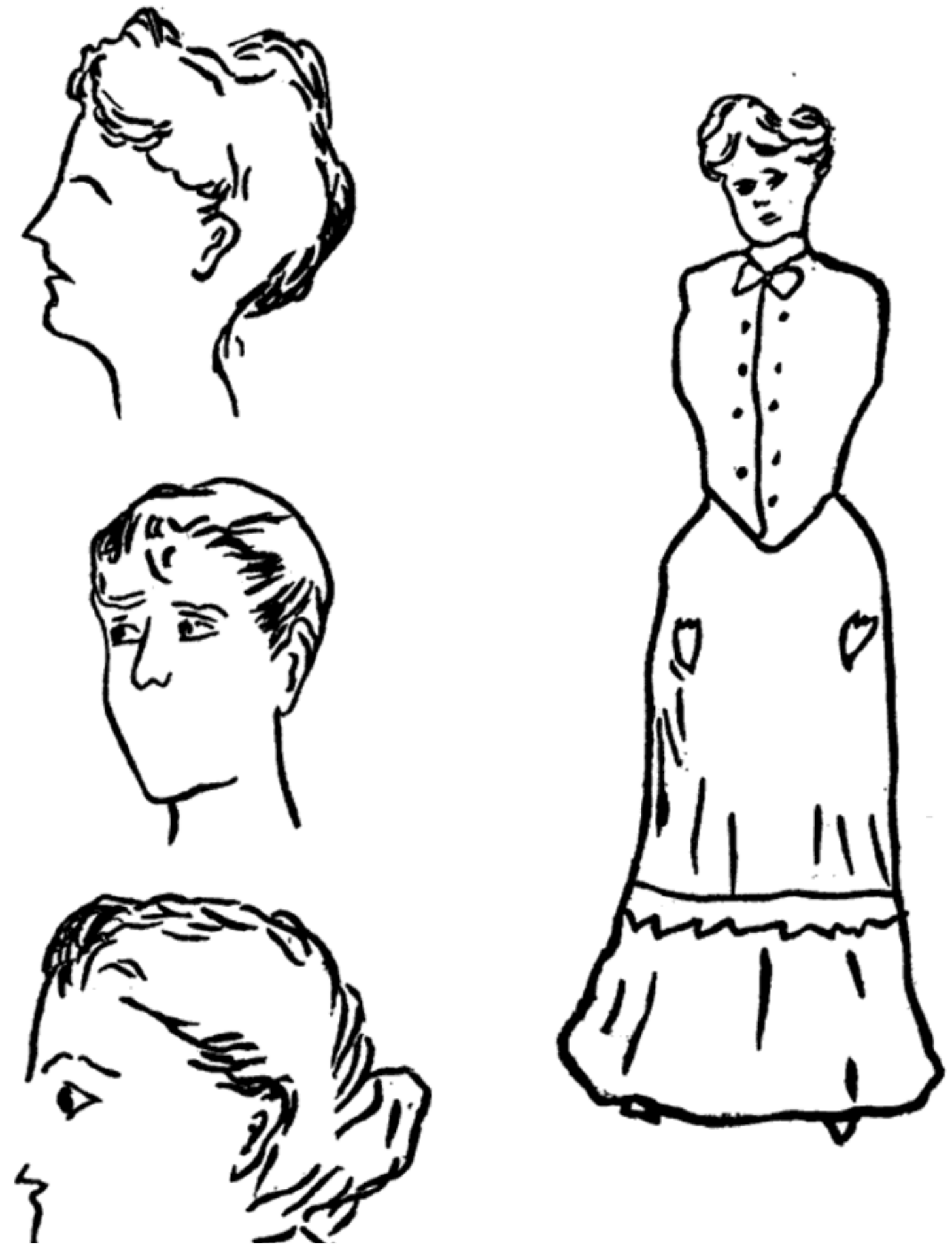

Figure 1. Examples of the "Unfinished Pictures" task, the forerunner of the modern WAIS-IV Picture Completion subtest (Binet \& Simon 1908/1916, p. 208). 


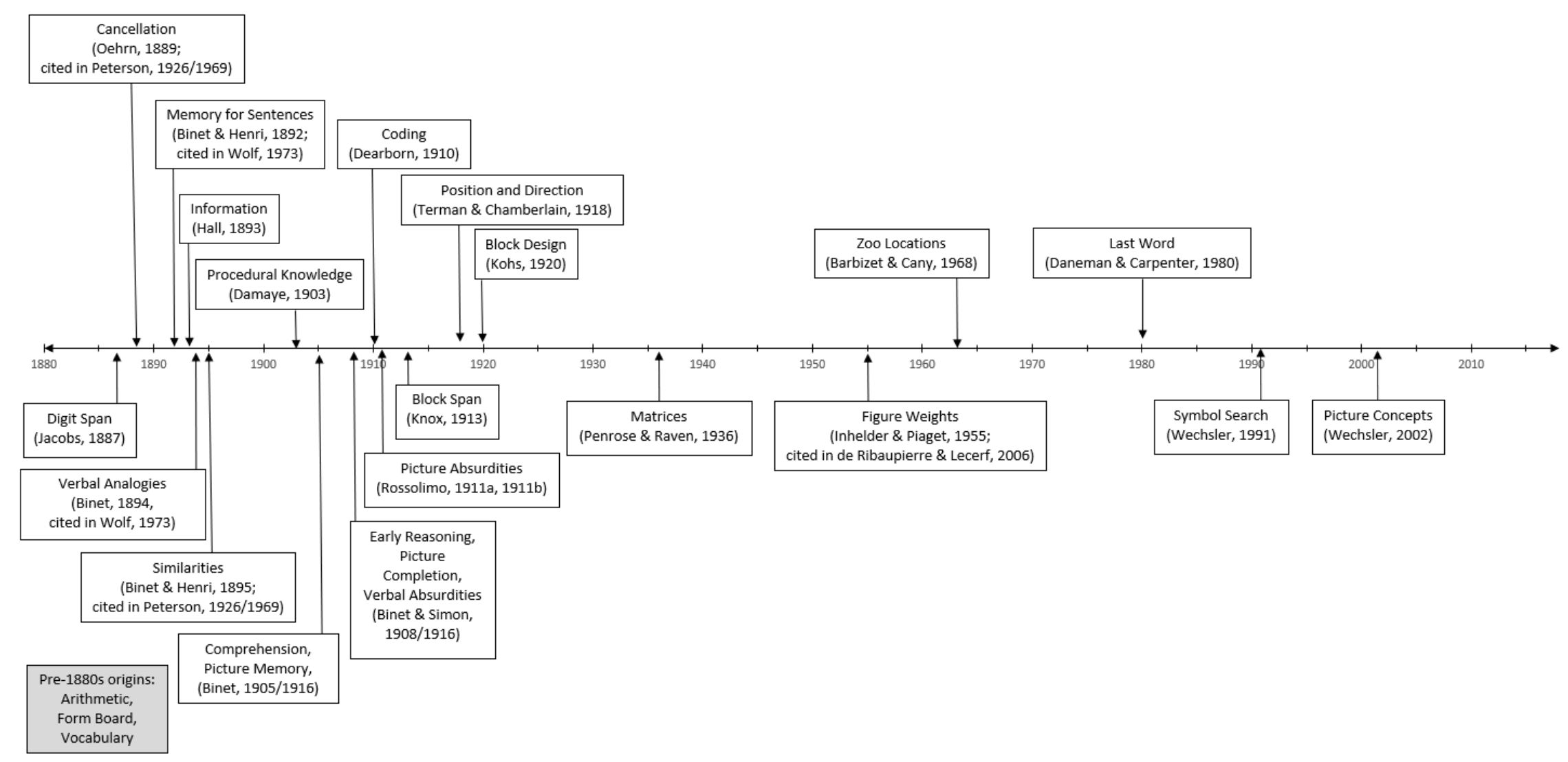

Figure 2. Timeline of our proposed candidates for the first known publication of Stanford-Binet 5 and modern Wechsler subtests. 